\title{
Unusual high-grade and low-grade glioma in an infant with PPP1CB-ALK gene fusion
}

\author{
Andrew Ng, ${ }^{1}$ Michael L Levy, ${ }^{2}$ Denise M Malicki, ${ }^{3}$ John Ross Crawford ${ }^{4}$
}

${ }^{1}$ Department of Child Neurology, Rady Children's Hospital University of California San Diego, San Diego, California, USA

${ }^{2}$ Department of Neurosurgery, University of California San Diego, San Diego, California, USA

${ }^{3}$ Department of Pathology, Rady Children's Hospital University of California San Diego, San Diego, California, USA

${ }^{4}$ Department of Neurosciences and Pediatrics, University of California San Diego, San Diego, California, USA

\section{Correspondence to} Dr John Ross Crawford, jrcrawford@ucsd.edu

Accepted 5 January 2019

\section{DESCRIPTION}

A previously healthy 3-month-old former 30-week premature girl presented with sudden onset altered mental status and cardiopulmonary arrest. ${ }^{1}$ CT scan showed a $10.2 \mathrm{~cm}$ hyperdense lesion in the right hemisphere with areas of acute haemorrhage causing subfalcine, uncal and inferior cerebellar herniation with obstructive hydrocephalus and diffuse cerebral oedema (figure 1A). She underwent craniotomy with gross total resection noted on postoperative MRI (figure 1B). Neuropathology showed densely cellular, pleomorphic astrocytes with high mitotic rate and glial fibrillary acidic protein (GFAP) positive staining consistent with high-grade glioma (figure 2A). A next-generation cancer gene sequencing panel revealed a novel PPP1CB-anaplastic lymphoma kinase (ALK) gene fusion from PPP1CB intron 5 and ALK intron 19. Variants of unknown significance were also noted on ECT2L, IRS2, KDM6A, NTRK1, TNFRSF17 and XBP1. Based on her young age and extensive surgical resection the decision was made not to undergo radiation or chemotherapy.

The patient had subsequent left hemiparesis, hypotonia, dysphagia and global developmental

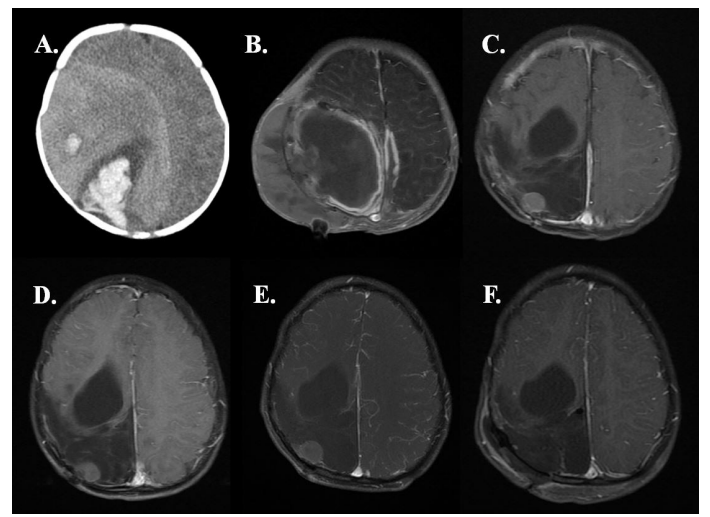

Figure 1 (A) Axial CT head at 3 months old from initial presentation showed right hyperdense lesion with acute haemorrhage, vasogenic oedema and midline shift from initial presentation. (B) T1-post contrast MRI brain showed gross total resection 9 days postoperative from first resection. (C) T1-post contrast MRI brain at 10 months old a month postoperative from endoscopic cyst fenestration and second resection showed a $1.5 \mathrm{~cm}$ rim-enhancing nodule in right parietal region. (D) Surveillance T1-post contrast serial MRI showed interval growth of new lesion at 2 years old and (E) 4 years old with final measurement $1.7 \mathrm{~cm}$. (F) Postoperative T1 MRI after third resection shows gross total resection of the nodule.

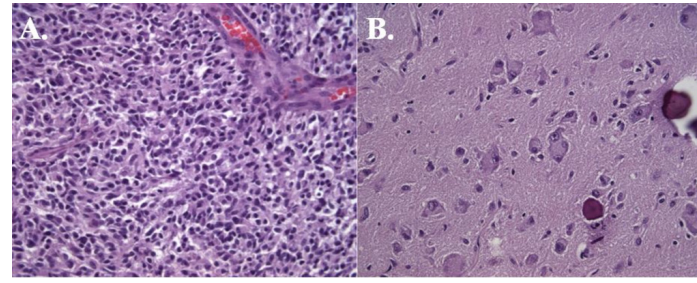

Figure 2 (A) Histology shows densely cellular, pleomorphic astrocytes with high mitotic rate and glial fibrillary acidic protein (GFAP) positive staining consistent with high-grade glioma. (B) Histology at second resection 4 years after initial diagnosis demonstrates a low cellular tumour with mature ganglionic cells and low mitotic rate consistent with a ganglioglioma.

delay. Surveillance MRI brain at 7 months old showed an asymptomatic trapped right ventricle causing leftward midline shift. She underwent endoscopic cyst fenestration and a second resection at 9 months old with biopsy showing gliosis. The 1-month postoperative MRI brain following the second resection showed a $1.5 \mathrm{~cm}$ rim-enhancing nodule in right parietal region second resection site (figure 1C).

Following her second resection, she remained disease free; however, subsequent surveillance MRI brain at 2 years old (figure 1D) and 4 years old (figure $1 \mathrm{E}$ ) revealed that the residual nodule grew slowly to $1.7 \mathrm{~cm}$ (figure 1E). Given concern about residual disease, decision was made to undergo a third gross total resection at 4 years old (figure $1 \mathrm{~F}$ ) that demonstrated a markedly different histopathology from the original high-grade glioma at diagnosis. The tumour was of low cellularity with mature ganglionic cells consistent with a diagnosis of ganglioglioma (figure 2B). Next generation cancer gene sequencing panel revealed the identical PPP1CB-ALK gene fusion along with variants of unknown significance of CASP8 and KDM6A.

ALK is a cell surface receptor tyrosine kinase that promotes downstream PI3K, JAK-STAT and MAPK pathways and has been associated with other various tumours including lymphoma, neuroblastoma and non-small-cell lung cancer. ${ }^{2}$ ALK gene fusions such as NPM-ALK and EML4-ALK have been reported to function as oncogenes in a variety of cancers. ${ }^{2}$

We previously reported on PPP1CB-ALK gene fusion as a novel mutation for primary high-grade glioma. ${ }^{1}$ Low-grade glioma recurrence following gross subtotal resection of a high-grade glioma has been reported. ${ }^{3}$ Our case highlights that there may be two unique histopathological tumours in the same patient with similar genetic changes. 
However, without additional functional studies, we cannot be sure if the PPP1CB-ALK fusion is a genetic driver in this disease. Furthermore, we do not know what role, if any, the variants of unknown significance may play. Our case adds to the literature regarding the complexity of infantile brain tumours.

\section{Learning points}

High-grade glioma of infancy may contain both high-grade and low-grade elements with similar tumour genetics.

- PPP1CB-anaplastic lymphoma kinase (ALK) gene fusion has been reported in a primary high-grade and low-grade glioma in the same patient.

- Further studies are needed to determine if PPP1CB-ALK gene fusion results in a functional fusion protein that may play a role in tumour growth and differentiation.
Contributors AN was responsible for the design and writing of the manuscript. MLL was responsible for the design and writing of the manuscript. DMM was responsible for the design and writing of the manuscript. JRC was responsible for the design and writing of the manuscript. All authors approve the contents of the manuscript.

Funding The authors have not declared a specific grant for this research from any funding agency in the public, commercial or not-for-profit sectors.

Competing interests None declared.

Patient consent for publication Obtained.

Provenance and peer review Not commissioned; externally peer reviewed.

\section{REFERENCES}

1 Aghajan Y, Levy ML, Malicki DM, et al. Novel PPP1C B-ALK fusion protein in a highgrade glioma of infancy. BMJ Case Rep 2016;10:1136.

2 Hallberg B, Palmer RH. Mechanistic insight into ALK receptor tyrosine kinase in human cancer biology. Nat Rev Cancer 2013;13:685-700.

3 Horbinski C, Dillon D, Pittman T. Low-grade recurrence of a congenital high-grade supratentorial tumor with astrocytic features in the absence of adjuvant therapy. Neuropathology 2011;31:286-91.

Copyright 2019 BMJ Publishing Group. All rights reserved. For permission to reuse any of this content visit

https://www.bmj.com/company/products-services/rights-and-licensing/permissions/

BMJ Case Report Fellows may re-use this article for personal use and teaching without any further permission.

Become a Fellow of BMJ Case Reports today and you can:

- Submit as many cases as you like

- Enjoy fast sympathetic peer review and rapid publication of accepted articles

- Access all the published articles

- Re-use any of the published material for personal use and teaching without further permission

For information on Institutional Fellowships contact consortiasales@bmjgroup.com

Visit casereports.bmj.com for more articles like this and to become a Fellow 